\title{
Estudo de caso individual: \\ uma perspectiva para o diagnóstico em psiquiatria
}

Antonia Elvira Tonus ${ }^{1}$

\section{Resumo}

O presente artigo procura desenvolver uma visão crítica dos métodos diagnósticos prevalentes no cenário conceitual da psiquiatria contemporânea, focando o presente desprestígio dado ao estudo de caso individual nas pesquisas e publicações científicas atuais. $O$ autor busca no fértil terreno da psicopatologia fenomenológica um breve olhar que possa revitalizar o estudo de caso como instrumento capaz e adequado para avaliação das complexidades do campo psíquico. Situa o estudo de caso individual como método fundamental na promoção de melhores categorias diagnósticas que servirão de fonte mais clara e lúcida para o avanço da neurociência e melhor aplicação na psiquiatria clínica.

Palavras-chave: Estudo de Caso Individual; Psicopatologia; Fenomenologia; Diagnóstico Psiquiátrico.

\section{Individual Case Study: a perspective for diagnosis in psychiatry}

\begin{abstract}
This article attempts to develop a critical view of prevalent diagnostic methods in the conceptual stage of contemporary psychiatry, focusing on the discredit given to individual case study in current research and scientific publications. The author seeks in the fertile ground of phenomenological psychopathology a brief look that can revitalize case study as a tool capable and suitable for assessment of the complexities of the psychic field. She places individual case study as a fundamental method in promoting better diagnostic categories that

\footnotetext{
${ }^{1}$ Médica Psiquiatra do Hospital do Servidor Público Estadual de São Paulo. Mestre em Psiquiatria e membro da Sociedade Brasileira de Psicopatologia Fenômeno-Estrutural. E-mail: antoniatonus@yahoo.com.br
} 
will supply more clearly and lucidly to the advancement of neuroscience and better application in clinical psychiatry.

Key-words: Individual Case Study; Psychopathology; Phenomenology; Psychiatric Diagnosis.

O homem é um todo, como o corpo que é, presentemente, a unidade corpo-alma na qual se mostra sua particularidade, na qual ainda dormem suas possibilidades, contando que já não se achem desenvolvidas; é sempre formado de maneira especial e, afinal, única. É um todo na expressão de seu curso vital; o que é liga-se no tempo e através do tempo se configura; o desenvolvimento de sua essência mostra o que ele é.

(K. Jaspers, "Psicopatologia geral", sem data, p. 675)

O campo conceitual da psiquiatria foi sempre marcado por impasses epistemológicos como a complexa relação cérebro-mente e a subseqüente contraposição de paradigmas biológicos versus psicológicos, assim como as noções de causalidade em doença mental.

Confrontados com estas questões, somadas a uma descabida procura de simplificação da psicopatologia aos moldes reducionistas, não poderíamos deixar de assistir a importantes dificuldades no campo do diagnóstico em psiquiatria. Seja no crescente número de categorias diagnósticas proposto pelos atuais sistemas oficiais de classificação das doenças mentais (DSM-IV-R e CID10), seja pelo método desses sistemas de construção de uma categoria diagnóstica pela somatória de sintomas.

Um atual questionamento sobre a necessidade de tantas categorias diagnósticas se impõe. Na evolução e configuração do campo de saber psiquiátrico, desde o início do século XIX, observamos diferentes posicionamentos nosográficos.

Lantéri-Laura (2000) em seu livro magistral sobre os paradigmas da psiquiatria moderna percorre um olhar sobre a história da psiquiatria em relação aos seus aspectos conceituais e doutrinais, entendendo sua evolução não 
como uma continuidade linear e de divisões temporais cronológicas, mas sim por meio de uma periodização na qual aponta as características plurilineares e descontínuas. Questiona qual periodização é mais adequada para dar conta do maior número de elementos que sofrem pouca modificação durante determinado período.

Nesta tentativa, o autor considera o conceito de paradigma de T. S. Khun, historiador das ciências. O que Khun denomina precisamente paradigma é o conjunto de conhecimentos transmitidos que constituem a ciência normal e que desempenham bem o seu papel e que servem de referência fundamental e eficaz a todos os saberes e a todas as questões centrais que se levantam. Quando a ciência normal já não explica mais os fenômenos observados esta passa a uma ciência em crise. Durante a crise, que pode durar bastante tempo, o paradigma desaparece e esta crise não se resolve até que um novo paradigma venha a ocupar o lugar do antigo e a prestar novos serviços. Assim o paradigma do heliocentrismo depois do geocentrismo, e o da relatividade e conseqüente teoria quântica após a física de Newton (Lantéri-Laura, 2000).

Lantéri-Laura (2000) concebe o papel de paradigma na psiquiatria como o que unifica toda uma série de representações teóricas e práticas. Segundo o autor, entre o final do sec. XVIII e o sec. XX sucederam-se pelo menos três paradigmas, descritos abaixo.

Desde o final do século das luzes até a metade do século XIX, podemos estabelecer um período marcado pelo postulado, segundo o qual o campo próprio da psiquiatria envolve uma afecção única, uma enfermidade, e que Pinel propôs denominar de Alienação Mental. Este período pode tomar como referencial de data de início o ano de 1793, quando a Comuna de Paris designa Pinel para o Hospital de Bicêtre. A psiquiatria tenderá a passar diretamente da Enciclopédia ao positivismo.

Para esta enfermidade única somente pode-se corresponder, para Pinel, uma única modalidade de terapêutica, que denomina tratamento moral da loucura. Este tratamento moral envolvia três aspectos fundamentais: era indispensável isolar o alienado de seus familiares, obrigá-lo a abandonar seu domicílio e mantê-lo em um estabelecimento especializado, com exclusão de qualquer outra patologia.

Os anos de 1850 a 1860 podem ser considerados como a data terminal deste período e, o autor propõe o ano de 1854, quando J.P.Falret, adversário indiscutível da unidade da patologia mental, publica o artigo de ruptura, que intitula "De la non existence de la monomanie". 
O paradigma da alienação mental sobreviveu ao outro, permanecendo em segundo plano, jamais desaparecendo por completo.

O segundo paradigma para Lantéri-Laura é o de Enfermidades Mentais no qual a patologia mental renuncia a constituir uma extraterritorialidade em relação à medicina e quer formar parte dela, como o resto de seus ramos. A medicina como um todo estava marcada pelos recursos da semiologia, da clínica e do prognóstico.

Tampouco se pode determinar o final deste segundo paradigma de uma maneira exata, mas parece razoável ao autor propor o ano de 1926, ano em que se celebra, em Genebra e Lausanne, o congresso em que E. Bleuler expõe em francês sua concepção sobre o "Grupo das esquizofrenias" e que somente pode-se abordar à luz do conceito de estruturas psicopatológicas. O novo paradigma se impõe de uma maneira bastante concreta como também conciliadora e, à sua maneira, um retorno a uma unidade. Configura-se então o paradigma das Grandes Estruturas Psicopatológicas.

Com a prevalência do conceito de estrutura, essa relação entre psiquiatria clínica e a psicopatologia irá se inverter radicalmente. A psicopatologia adquire um caráter predominante e a psiquiatria clínica representará sua aplicação derivada. Este período se manteve por muito tempo e o autor Lanteri-laura propõe a data para sua finalização, o outono de 1977, quando a psiquiatria perde seu maestro Henri Ey.

O paradigma das grandes estruturas se acomodava bem aos meios terapêuticos dos anos 1930 a 1950, porém com a introdução da clorpromazina no cenário terapêutico e subseqüente proliferação de novos psicotrópicos observamos uma nova tendência de ajustar os efeitos dos psicotrópicos a novas categorias diagnósticas.

Encerro, em linhas gerais, a citação de Lanteri-Laura sobre como ocorreu a passagem de um paradigma a outro nos quase duzentos anos que se propôs a analisar.

Contemporâneos que somos da pós-modernidade, termo de gênese histórica vaga e limites fluidos, convivemos com a ocorrência de vários paradigmas de limites imprecisos que acontecem simultaneamente. No panorama de vários agrupamentos conceituais multifacetados em várias direções, observamos a tendência de valoração de um paradigma centrado na quantificação e objetivação das ciências naturais. 
Este artigo procura focar a importância da revitalização do estudo de caso individual sob a perspectiva fenomenológica, como método de investigação psicopatológica suficiente e capaz de abarcar a complexidade e as particularidades dos fenômenos psíquicos contribuindo para o cenário conceitual da nosografia contemporânea.

A ideia inicial de desenvolver este tema ao longo de toda a história da psiquiatria nos colocaria diante de dificuldades como: qual recorte dos períodos históricos serviria de tessitura de base para discorrer o tema? A análise conceitual sobre o método: "estudo de caso individual" (e não apenas relatos de casos) parecia inicialmente inexistente na literatura e só depois de sucessivas conjecturas o tema foi emergindo de forma intrínseca nas obras autorais dos grandes psiquiatras fenomenologistas.

Para o entendimento e valoração do estudo de caso individual como método central na psicopatologia, escolho abrir a investigação na obra de Karl Jaspers, transpassando por E. Minkowski e L. Binswanger como representantes essenciais da fenomenologia clássica, e posteriormente, analisar como o tema deságua no cenário da psiquiatria conceitual contemporânea.

\section{Relevância do estudo de caso na obra de Jaspers}

Jaspers, na introdução do livro "Psicopatologia geral", refletindo sobre preconceitos teóricos, nos alerta sobre as diferenças entre as ciências naturais e o campo da psicopatologia. As primeiras se estruturam em teorias amplas, bem fundamentadas que fornecem ao entendimento dos fatos uma base uniforme. Cita como exemplo a teoria atômica e a citologia. Na segunda, psicopatologia, não há nenhuma teoria dominante desta natureza. "Ao invés de descer aos últimos elementos, mecanismos e regras, a partir dos quais deve ser compreendido todo processo psíquico, seguimos apenas caminhos particulares, trabalhamos com métodos particulares que nos apresentam apenas aspectos particulares da vida psíquica" ( Jaspers, sem data, p. 29).

Querer reduzir a vida psíquica a alguns axiomas universais e assim dominá-la, em princípio é um falso propósito, por ser impossível. As idéias teóricas de que fazemos uso e que possuem uma semelhança formal com as teorias das ciências naturais não são senão tentativas (hipóteses) para fins de conhecimentos bem 
delimitados e não para o conhecimento da alma no seu todo. (Jaspers, sem data p. 30)

Na exposição sobre métodos, Jaspers, ao referir-se à casuística, diz que a base experimental da psicopatologia é constituída de casos singulares, sendo a casuística a descrição desses casos e do histórico dos pacientes, desde a exposição de fenômenos particulares até uma biografia completa.

No avançar de sua obra, o autor, no terceiro capítulo: Sobre o Sentido e o Valor das Teorias propõe que as teorias psíquicas partem de fenômenos psíquicos individuais, de forma que as ideias teóricas vêem nestes o paradigma de todo evento psíquico.

Jaspers insiste na importância de uma psicopatologia que se baseie nas teorias, sabendo manipulá-las conscientemente, porque as conhecem, não dando a qualquer delas significação que exceda a importância relativa de um instrumento metodológico. Infelizmente quase cem anos após estas importantes observações nos encontramos diante de uma sobrevalorização dos métodos estatísticos epidemiológicos que compõem, entre outros, o paradigma da quantificação e objetivação das ciências naturais.

Para uma concepção da totalidade da vida psíquica, Jaspers apropria-se da filosofia kantiana para compreender a complexidade da vida psíquica mostrando o quanto se torna ingênua e tarefa inatingível, o desejo de capturar o todo psíquico.

Kant conceituou e por forma grandiosa mostrou o seguinte: quando quero apreender o todo, seja o mundo, seja o homem, o objeto escapa-me, porque o que pretendo, a idéia (tarefa a investigar infinitamente), não é finitude precisa e conclusa. $\mathrm{O}$ que conheço nunca é o mundo, e sim alguma coisa no mundo: o mundo não é objeto, mas ideia. (Jaspers, sem data, p. 678)

Jaspers discorrerá em mais de duzentas páginas, sobre nosologia, eidologia e biografia, já que acredita que seja tarefa do psicopatologista trabalhar com estas vertentes simultaneamente. Jaspers, na sua concepção da totalidade da vida psíquica, diz:

não reconhecemos nem o todo da vida psíquica, nem o todo de uma personalidade individual, e sim dirigimos nossas intenções para esse todo mediante totalidades construídas: mediante o curso vital conjunto, a natureza variada do homem, as unidades nosológicas; totalidades que ainda não vêm a ser, elas próprias, o 
todo, e sim, simplesmente, padrões finais, resultados de análises, que nos apontam o caminho para a apreensão possível do todo, sem que ainda consigamos apossar-nos do todo. (Jaspers, sem data, p.673)

Ainda sobre a relação entre o particular e o todo analisa que o conhecimento fecundo está sempre oscilando entre os elementos e o todo. É certo que existe, em relação ao todo, uma intuição, a qual, porem, só se faz clara pela análise dos elementos. Aliás, pode-se trabalhar facilmente, se bem que superficialmente, com os elementos isolados; mas só quando vistos em relação com o todo é que se os apreendem por forma realística.

Jaspers brilhantemente, mesmo antes da vigência dos sistemas classificatórios atuais nos alerta no capítulo A sintese dos quadros mórbidos:

$\mathrm{Na}$ psicopatologia geral, cogita-se, inicialmente, de fenômenos particulares por si: alucinações, fuga de idéias, idéias delirantes. Concebem-se isoladamente e considera-se aquilo que neles coincide, seja qual for a doença em que aparecem. Na realidade, porém, cada fenômeno ou manifestação tem nuances variadas conforme os diversos doentes, não consistindo, apenas, no desenvolvimento mais ou menos pleno, e sim no fato de que, dentro do mesmo desenvolvimento, todos os processos psíquicos tem suas modificações, as quais decorrem, em parte, da individualidade diversa, em parte das várias alterações psíquicas, que podem ser as mais gerais. É freqüente sentirmos mais do que formulamos conceitualmente estas nuances. Se os fenômenos constituíssem formações rígidas, sempre idênticas, poder-se-iam considerar os quadros nosológicos formações mosaiciformes, variadamente compostas de pedras individuais, sempre idênticas. Importaria, apenas, nomear estas pedrinhas sempre iguais; ver, para cada uma, em que enfermidade com mais freqüência costuma representar-se; e pela adição das freqüências, chegar ao diagnóstico. Esse método de uma estruturação errada em mosaico, empregado muitas vezes por forma rudimentar, apega-se, todavia, a superficialidades, tornando mecânicos a investigação psicopatológica e o diagnóstico e apenas petrificando o que até o momento se adquiriu. (Jaspers, sem data, p. 683)

Jaspers defendeu ao longo de sua obra, que a atividade essencial no campo psicopatológico ainda é a análise do caso particular. 


\section{Fenomenologia psiquiátrica e o estudo de caso individual}

No campo do saber da fenomenologia psiquiátrica, questões como experiência, vivências, intersubjetividade, assim como vivências da temporalidade e espacialidade, são seus grandes pilares e é no estudo de caso individual que temos o grande e fundamental exercício deste saber na análise minuciosa destas vertentes.

Expondo um breve olhar sobre esta perspectiva, já que uma maior explanação seria inviável neste artigo, situo na obra de Arthur Tatossian alguns pontos relevantes sobre fenomenologia e psiquiatria.

Para o autor (Tatossian, 2006), a fenomenologia tem por ambição mostrar que há em cada experiência mais do que o empirismo comum reconhece.

O que há na experiência, para além do fato objetivo, é a essência daquilo que se encontrou, sua forma de ser, seu "como" que se junta ao "que" do qual a ciência abstrai o dado da experiência. Essa essência é o que torna possível o dado, o que o constitui transcendentalmente. Mas isso que é propriamente fenomenológico, não é a noção de essência, é o que nesta é "visível", acessível à visão.(Tatossian, 2006 p.35)

A fenomenologia não pretende explicar, mas clarificar a experiência psiquiátrica, ou seja, torná-la transparente quanto à essência (Tatossian, 2006).

A estrutura eidética que fornece o caminho fenomenológico não é causa dos fatos psicopatológicos. Ela mostra simplesmente o que os torna possíveis e é, neste sentido, uma experiência "apriórica". A experiência fenomenológica é, portanto, uma experiência dupla, ao mesmo tempo empírica (no sentido comum) e apriórica. Esta ambição nada tem de arbitrário porque a psiquiatria é o estudo de Presenças humanas concretas e individuais e que só tal experiência mista lhe torna acessível não somente o modo específico da Presença, mas também o "andamento da Presença" particular. Não lhe é suficiente, por exemplo, ver por ocasião da experiência de um melancólico o a priori da imobilização do viver - a estagnação do tempo vivido ou a inibição do devir- 
mas ela deve ver também efetivamente a particularidade até o nível mais individual - pois não somente os melancólicos, mas também os obsessivos e os esquizofrênicos comportam esta estagnação (Tatossian, 2006).

O autor, assim como Jaspers pontua a importância de no campo psíquico não termos sintomas patognomônicos e, portanto, a necessidade de acessar o indivíduo nas suas vivências particulares.

A experiência própria às ciências da natureza aborda o doente como organismo psicofísico, dissociável em aparelho somático e em aparelho psíquico, submetido às leis causais. As outras experiências psiquiátricas do tipo psicológico compreensivo, hermenêutica, fenomenológica ou "atmosférica" não dispõem mais que uma verificação "consensual", mas elas não são por isso menos empíricas, mesmo se seu empirismo é de um outro tipo que não o usual. O autor (Tatossian, 2006) propõe que a experiência fenomenológica pode generalizar a essência que conquistou sobre um caso único enquanto tal generalização seria ilegítima na experiência empírica tradicional.

Binswanger (1977), na tentativa de destilar a essência da excentricidade, parte da descrição de cinco casos individuais:

Acreditamos que podemos contentar-nos com esses exemplos. Pois na apreensão fenomenológica da essência, o que importa - ao contrário do que ocorre na ciência natural - não é o acúmulo tão grande quanto possível de exemplos ou fatos, mas a apresentação ou rememoração "exemplar" de fatos humanos singulares e a apreensão e fixação das "essências puras" sobre semelhante "base", ou ponto de partida, exemplar. (Binswanger, 1977, p.80)

A partir da investigação destes casos, Binswanger penetra nas formas de "ajustamento" e "adequação" destes indivíduos, procurando compreendê-los a partir de seus próprios mundos e de suas particularidades, observando a "mundanidade" da excentricidade como um "mundo do través ou da distorção", conduzindo a um fracasso ou malogro existencial no convívio com os outros.

Minkowski já havia pontuado a importância de conceder grande valor ao que experimentava o clínico na sua relação com o paciente. Em uma passagem célebre do seu livro "O tempo vivido", no seu capítulo orientação geral de pesquisa, fala das próprias reações dos clínicos na presença do doente como meio de investigação dos problemas mentais (Minkowski, 2005).

Descreve um estudo de caso: durante a estadia do paciente na clínica, Minkowski o via diariamente. Nas primeiras frases trocadas nada de doentio é 
percebido, porém posteriormente volta a falar sucessivamente das mesmas ideias delirantes, e então Minkowski sente surgir nele um sentimento particular, sentimento que ele traduzirá mentalmente por: "Eu sei tudo sobre ele". "Um dia, a força de ouvi-lo desenvolver as mesmas idéias, sinto surgir em mim um sentimento que traduzo mentalmente por estas palavras: já sei tudo sobre ele." (Minkowski, 2005, p.165).

Este sentimento o faz refletir: O que realmente quer dizer? Se ele ignora praticamente tudo sobre o passado deste doente? A impressão de saber tudo sobre o doente não é acompanhada de uma satisfação, de traduzir alguma coisa de positivo; ao contrário, sente como uma perda, um empobrecimento, como uma violação ocorrida na relação habitual entre dois seres humanos.Há sempre algo de misterioso no ser humano. Neste caso, o doente causa a impressão de algo imóvel, sem vida; toda profundidade desapareceu de sua vida atual; se encontra diante do interlocutor somente sobre o plano das ideias delirantes.

Ainda no livro "O tempo vivido", no capítulo "Dados psicológicos e fenomenológicos em um caso de melancolia esquizofrênica", Minkowski (2005) passa dois meses morando com um doente na qualidade de médico particular, no ano de 1923. Clinicamente o paciente apresentava ideias de ruína, culpabilidade, castigo iminente e ideias de perseguição. Tratava-se provavelmente de uma melancolia delirante, e o paciente esperava todos os dias que no dia seguinte pela manhã seria sua execução, considerando também que em todas as partes existiam todas as classes de resíduos para serem introduzidos em seu corpo antes de fazê-lo morrer; denominava a "política dos restos".

Esta impressão que o sujeito esta reduzido a bem pouco induz Minkowski a ver estas alegações delirantes como uma alteração radical de suas relações com a temporalidade. Continua:

Quando lhe digo: Você deveria crer que quando eu lhe asseguro que não esta ameaçado por nada, até o presente, minhas previsões tem se realizado sempre. Ele responde: Eu admito que até o presente você sempre tem tido razão, mas isto não significa que irá você a tê-la amanhã. Sem dúvida, constitui um transtorno profundo da atitude geral com respeito ao futuro. O tempo se fraciona aqui em elementos isolados, que na vida normal, integramos entre si com toda naturalidade.(Minkowski, 2005, p.174) 
Minkowski denomina então de transtorno gerador e, sem esboçar uma tipologia de tais transtornos, propõe qualificar esta alteração da temporalidade como transtorno gerador da melancolia.

Binswanger (1987), em seu livro "Melancolia e mania", obra escrita quase aos oitenta anos, manifesta, portanto, um pensamento de uma vida. Neste livro o autor se propõe a compreender o mundo do doente através de alguns estudos de casos ao longo de toda a sua obra, permitindo um profundo estudo fenomenológico, não mais nos parâmetros da fenomenologia descritiva e sim na fenomenologia de retorno ao pensamento husserliano: fenomenologia genética. Propõe que as objetividades temporais: passado, presente e futuro, são constituídas pelas intencionalidades da retenção, apresentação, protenção, funcionando não de forma articulada na melancolia e na mania.

Para Binswanger a temporalidade melancólica é caracterizada pelo relaxamento dos laços entre retenção, apresentação e protenção. Na melancolia, há para o autor uma "retessitura" na vivência temporal marcada por uma constante autocensura em que a fórmula psíquica seria: " se eu não tivesse feito isso... eu não estaria como estou...", comportando um duplo aspecto : aquele da possibilidade (Se), mas aquele do passado, do já feito, do imutável. É um campo de possibilidade vazia onde a retenção se infiltra de momentos de protenção. A apresentação, o "sobre o que", também está alterada. O fluxo do tempo e também do "pensamento" em geral está parado. A experiência melancólica é de um campo de possibilidades que desapareceu e de uma certeza inabalável.

As descrições acima sobre a melancolia servem de exemplo de como o autor partindo do estudo de caso individual elabora, com tamanha profundidade e complexidade, uma compreensão da Melancolia abrindo um fértil campo de pesquisa para possíveis abordagens terapêuticas.

\section{A psiquiatria contemporânea pode prescindir da psicopatologia e do estudo de caso individual?}

A questão nasce da atual prevalência de estudos empíricos, quantitativos ou que trabalham com metodologia estandardizada, publicados nas principais revistas de impacto no campo da psiquiatria, pesquisas estas, embasadas nos códigos de classificação nosográficas oficiais assim como em escalas e entrevistas estruturadas. Esta realidade não impede ou paralisa as pesquisas de 
natureza mais conceituais e qualitativas que buscam beber da rica fonte do corpo de saber da psicopatologia.

Joel Paris (2008), em uma visão crítica sobre a psiquiatria contemporânea, abordando temas controversos como causalidade, reducionismo, achados das pesquisas genéticas e de neuroimagem, adverte que ainda estamos sem uma resposta para as causas das doenças mentais. No campo da psiquiatria as doenças surgem da interação de muitos fatores.

O autor critica a busca por marcadores biológicos dentro de um paradigma de causalidade linear, desconsiderando o complexo sistema mental. Argumenta em três linhas de raciocínio. Primeiro, com poucas exceções, nenhum fator de risco biológico leva de maneira previsível à doença. Mesmo em doenças mentais com forte componente genético, tal como esquizofrenia ou transtorno bipolar do humor, nenhum gene isolado é associado com a doença. Segundo, genes associados com doença podem nunca se expressarem a menos que o indivíduo vivencie um determinado ambiente. Estudos da Epigenética examinam como os genes podem ser acionados ou não pelo ambiente. Por último, a dificuldade de relacionar genótipos com fenotipia em categorias diagnósticas muito amplas e heterogêneas usadas nas pesquisas pautadas no DSM-IV-R ou CID-10.

Paris (2008) repara para o fato de que dado à característica complexa da mente humana (sistema capaz de produzir consciência, livre arbítrio e comportamentos complexos) devemos estar atentos para evitar tendências reducionistas que funcionam em sistemas de maior simplicidade. Psiquiatras esperam que avanços na neurociência promovam avanços no tratamento dos doentes, mas paradoxalmente, o grande avanço na psicofarmacologia ocorreu décadas atrás, antes que qualquer mecanismo de ação das drogas tivesse sido elucidado.

Messas (2008) em uma reflexão sobre a psicopatologia contemporânea postula: "todo o regime epistemológico desta, orbita em torno da psicofarmacologia e da epidemiologia"(Messas, 2008 p.217). “A necessidade da psicopatologia dominante em oferecer consistência aos aportes da psicofarmacologia remete, portanto, à modalidade de incorporação da biologia à psiquiatria e, por extensão, da psiquiatria dentro do escopo da medicina"(Messas, 2008, p.217).

A necessidade da epidemiologia é de outra índole: passa pelo esforço de tornar a linguagem psicopatológica a tal ponto simplificada que permita, simultaneamente, uma homogeneização 
das diversas escolas e tradições de pensamento e a viabilização de investigações de campo em escala mundial." (Messas, 2008, p. 217)

Para o autor, a noção de determinismo absoluto do psiquismo avançou para o plano de frente da ciência contemporânea desde os anos 50 do século $X X$ com o impacto dos agentes farmacológicos trazendo como características e conseqüências: a busca pela reversibilidade completa na doença mental, a simplificação da psicopatologia, a limitação do fator humano, o estreitamento da função terapêutica, a redução da ciência biológica ao estudo do cérebro, negligência para as noções de indeterminação e complexidade na psiquiatria.

\section{Considerações finais e propostas}

As pesquisas realizadas pelas neurociências são, sem dúvidas, impressionantes. Mas a aplicação no campo da psiquiatria clínica com subseqüente melhoria para o tratamento dos doentes mentais ainda não se mostra evidente. Este fato nos coloca diante da importância de reconsiderar o conceito de doença mental e os métodos para seu diagnóstico. Definições mal concebidas das doenças mentais, com limites imprecisos e heterogêneos, como por exemplo, o conceito de depressão maior dificultam ou até podem conduzir ao fracasso dos estudos genéticos em psiquiatria.

Messas (2010) em um artigo de impactante contribuição para o campo epistemológico na psiquiatria, sugere a fenomenologia como uma rica e capaz fonte de saber que possa contribuir para verdadeiros avanços na psiquiatria biológica. Adverte sobre as falhas e riscos da psiquiatria contemporânea basearse em paradigmas de inspiração cartesiana. $\mathrm{O}$ autor pontua que o estudo de caso individual emerge como único instrumento metodológico capaz de desvendar a complexidade dos fenômenos psíquicos.

Para Sonenreich e Estevão (2007) pensar a psiquiatria separando elementos isolados, para depois somá-los, seria impróprio. Os autores analisam que as alterações do relacionamento interpessoal, as interpretações dadas às situações vividas, a organização das condutas e das comunicações, podem ser muito mais adequadamente estudadas e tratadas, pensando em estruturas, sistemas e configurações. "Os "módulos" não são nossa escolha no "nível" das doenças psíquicas. Preferimos, para estudar as atividades normais e patológicas do psiquismo, abordagens sistêmicas, estruturadas, de conjuntos em relação" (Sonenreich, Estevão, 2007, p.75). 
Para os autores, a visão do ser humano é sugerida principalmente pelas ideias de liberdade de escolhas. Reconhecem a influência de elementos biológicos, psicológicos ou sociais para a existência humana, mas valorizam para a prática da psiquiatria, mais a parte de liberdade de opções do que a parte determinista.

Os autores propõem um postulado epistemológico, marcado por um esforço em manter, no exercício da profissão, a coerência entre um sistema de conceber o homem, a medicina, e as ciências em geral.

Nas considerações finais deste artigo escolho estes autores acima citados, como representantes de uma psiquiatria que se aplica em compreender o ser humano nas suas particularidades e na sua complexidade, ofertando ao campo de saber psicopatológico um fértil terreno de propostas que possam nos conduzir a melhores abordagens terapêuticas

Sonenreich e Estevão (2007) consideram fundamental encarar o ser humano como único, não como "exemplar" de uma espécie. Para o ser humano é essencial a sua relação com os outros, com o mundo e as significações das quais ele participa. Afirmam:

"Fazemos psiquiatria para pessoas no seu mundo" (Sonenreich, Estevão, 2007, p.19)

\section{Referências Bibliográficas}

Binswanger, L. (1977). Três formas da existência malograda. Rio de Janeiro: Zahar Editores.

(1987). Mélancolie et manie. Paris: Presses Universitaires de

France.

Jaspers, K. (Sem data). Psicopatologia Geral. São Paulo, Rio de Janeiro: Atheneu.

Lantéri-Laura, G. (2000). Ensayo sobre los paradigmas de La psiquiatria moderna. Madrid: Editorial Triacastela.

Messas, G. P. (2008). Psicopatologia Fenomenológica e Psicofarmacologia: um Desafio para a Contemporaneidade. In: Messas G (organizador) Psicopatologia Fenomenológica Contemporânea (pp. 215-243). São Paulo: Roca. 
(2010). A Phenomenological Contribution to the Approach of Biological Psychiatry. Journal of Phenomenological Psychology, v. 41, pp. 180-200.

Minkowski, E. (2005). Le temps vécu. 2a. édition. Paris: Presses Universitaires de France.

Paris, J. (2008). A Critical View of Contempory Psychiatry. New York: Oxford University Press.

Sonenreich, C, Estevão, E. (2007). O que psiquiatras fazem: ensaios. São Paulo: Casa Editorial Lemos.

Tatossian, A. (2006). A fenomenologia das psicoses. São Paulo: Escuta. 